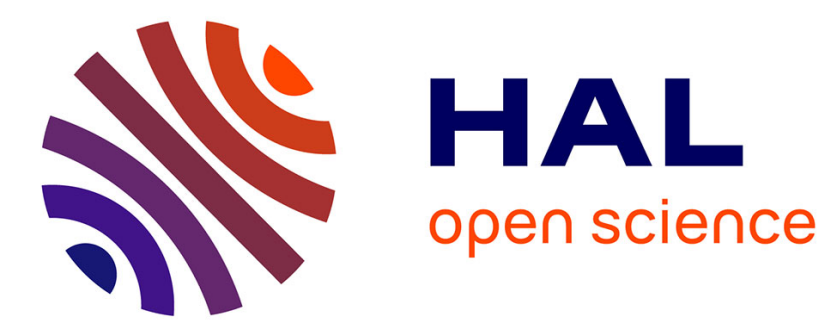

\title{
Fast determination of gas-liquid diffusion coefficient by an innovative double approach
}

\author{
Feishi S. Xu, Melanie Jimenez, Nicolas Dietrich, Gilles Hébrard
}

\section{To cite this version:}

Feishi S. Xu, Melanie Jimenez, Nicolas Dietrich, Gilles Hébrard. Fast determination of gas-liquid diffusion coefficient by an innovative double approach. Chemical Engineering Science, 2017, 170, pp.68-76. 10.1016/j.ces.2017.02.043 . hal-01606812

\section{HAL Id: hal-01606812 https://hal.science/hal-01606812}

Submitted on 18 Jul 2021

HAL is a multi-disciplinary open access archive for the deposit and dissemination of scientific research documents, whether they are published or not. The documents may come from teaching and research institutions in France or abroad, or from public or private research centers.
L'archive ouverte pluridisciplinaire HAL, est destinée au dépôt et à la diffusion de documents scientifiques de niveau recherche, publiés ou non, émanant des établissements d'enseignement et de recherche français ou étrangers, des laboratoires publics ou privés. 


\title{
Fast determination of gas-liquid diffusion coefficient by an innovative double approach
}

\author{
Feishi Xu, Mélanie Jimenez, Nicolas Dietrich and Gilles Hébrard \\ LISBP, Université de Toulouse, CNRS, INRA, INSA, Toulouse, France
}

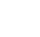

\section{Abstract}

Two effective mathematical approaches based on the probability and statistics theory are proposed for obtaining the oxygen diffusion coefficients in gas-liquid systems. The first method was to apply PLIFI (Planar Laser Induced Fluorescence with Inhibition) to the wake of an isolated bubble rising in water. The chi-squared distribution was introduced to describe the concentration field of oxygen diffusion. The approach provided a feasibility to evaluate the gas-liquid diffusion coefficient by analyzing the temporal evolution of the oxygen spot area on the experimental images. The second method was conducted through a flat air-liquid interface in a Hele-Shaw cell filled with quiescent deoxygenated water. By analogy, the evolution of the oxygen concentration with time was demonstrated to be characterized by the law of inverse gamma. The diffusion coefficient was estimated from the dissolved oxygen concentrations measured by a Clark-type probe at a specific position in the liquid phase. This technique was also tested experimentally for different probe locations to minimize their influence on the diffusion coefficient determination. Moreover, the non-perturbation property of the technique was validated by visualizing the oxygen concentration field around the probe through the colorimetric method. The diffusion coefficients of oxygen in water calculated from the two measurements were almost identical: $2.00 \times 10^{-9} \mathrm{~m}^{2} \cdot \mathrm{s}^{-1}$ which is in good agreement with the literature. The specificity of these two methods is that they do not require the properties of the fluid (such as the saturation concentration) or to calibrate the probe. Thus, it provides an alternative approach to evaluate the gas-liquid coefficient accurately and quickly, even in the complex media cases, such as biological media. 


\section{Introduction}

The quantification of mass transfer phenomenon is important in the industry. The determination of physical properties in the transport process, such as the diffusion coefficient and liquid-side mass transfer coefficient, would be helpful to understand the transport mechanism deeply. Concentrating on the diffusion regime which is characterized by a diffusion coefficient $D$, it physically represents a migration of molecules of a constituent under the effect of a potential chemical gradient. The first law of diffusion was established by Fick (1855). By analogy with Fourier's law governing the transfer of heat, the diffusive flux can be expressed as

$$
J=-D \nabla C
$$

where $J$ is the diffusive flux $\left(\mathrm{kg} \cdot \mathrm{m}^{-2} \cdot \mathrm{s}^{-1}\right)$ and $\nabla C$ denotes the concentration gradient. The subsequent researches in this domain are intensive and several measurement techniques have been developed: the steady state method (Tham et al., 1967), capillary cell method (Gubbins et al., 1966; Malik and Hayduk, 1968), laminar jet method (Duda and Vrentas, 1968; Ferrell and Himmelblau, 1967), and absorption measurement (Sovová and Procházka, 1976). Other techniques based on the Taylor dispersion (Baldauf and Knapp, 1983), the use of polarographic sensors (Ho et al., 1986; Ju and Ho, 1985) and bubble size calculation (de Blok and Fortuin, 1981; Wise and Houghton, 1966) can also be considered. However, the classical determination methods present some limitations due to hydrodynamic perturbation, natural convection, necessity of transparent liquids, long response time, impact of the liquid media, and so on (Blackadder and Keniry, 1973, 1974). Furthermore, it has to be noted that most of the measurements concern gas-gas or liquid-liquid systems and the knowledge of the case persisting in the gas-liquid system is not sufficient.

More recently in laboratories, the technique by using microprobes has been adopted because of its simplicity of experimental configuration (Bowyer et al., 2004; Jamnongwong et al., 2010). For instance, Hebrard et al. (2009) assessed the impact of surfactants on the oxygen diffusion coefficient with a Clarktype probe in a stirred cell. This kind of technique always requires the insertion of measuring instruments (ex. pressure, concentration meters) which may bring a perturbation to the system. Due to the non- 
intrusive advantages, optical techniques such as interferometry (Guo et al., 1999), are developed to characterize the diffusive process. The technique of interferometry could quantify the transfer in a liquid phase through the change of refractive index induced by the presence of dissolved gas (Roetzel et al., 1997; Wylock et al., 2011). However, the process for obtaining the relation between the refractive index and dissolved gas concentration is always complicated and time-consuming. The planar laser-induced fluorescence (PLIF) is another optical method widely applied to characterize the mass transfer in the gas-liquid system (Bouche et al., 2013; Sancho et al., 2016; Stamatopoulos et al., 2015). The principle of PLIF is to introduce a fluorescent dye into the liquid phase illuminated by a laser sheet. According to the properties of different fluorescent dyes, the fluorescence intensities can be affected by one or multiple the fluid conditions (the presence of specific gas, $\mathrm{pH}$ value, and temperature). The state of mass transfer can thus be obtained from images of the studied solution in the enlightened area recorded by cameras. Due to the advantages (ex. fast response, no flow disturbance, high resolution), several PLIFbased studies have been carried out to evaluate the gas-liquid diffusion coefficient (Bork et al., 2005; Dietrich et al., 2015; Jimenez et al., 2012a, 2012b) with good accuracy.

Overall, techniques to measure the diffusion coefficient are diverse, each of which displays low measurement uncertainties. Nevertheless, if a comparison is made between the diffusion coefficient values obtained by these techniques, a big gap appears. For example, the values in the literature for the diffusion coefficient of oxygen in water range between $0.7 \times 10^{-9} \mathrm{~m}^{2} \cdot \mathrm{s}^{-1}$ and $2.5 \times 10^{-9} \mathrm{~m}^{2} \cdot \mathrm{s}^{-1}$ for a given temperature $\left(20^{\circ} \mathrm{C}\right)$. The empirical equations or semi-empirical ones, commonly used in the literature and the industry, being established from these experimental results, it is not surprising that their validity is, in some cases, questionable.

Therefore, the objective of this study is to provide new insight into this domain. Two different methods are proposed to obtain the diffusion coefficient of oxygen in water in different devices. In the first method, PLIF with inhibition (PLIFI) technique was used to measure the mass transfer in the wake of an isolated bubble rising in a column. In the second one, a probe was used to measure the concentration of dissolved oxygen passed through a flat air-liquid interface in a Hele-Shaw cell. With the experimental data, both diffusion coefficients were calculated based on the effective mathematical models: the chi- 
squared distribution and the law of inverse gamma, respectively. The final coefficient could be determined by comparing these two results.

\section{Materials and Methods}

\subsection{First Method: PLIF with inhibition in a bubble column}

PLIF is an optical technique which has already been proved powerful for the mass transfer visualization (Asher, 2009; Jimenez et al., 2013). In PLIF with inhibition (PLIFI), the ability of some molecules called "quenchers" to inhibit the fluorescence dye is considered. Oxygen, which is of prime interest in a series of studies (Dani et al., 2007; Jimenez et al., 2013; Kück et al., 2010, 2012), has been known as an excellent quencher. The quenching effect is usually considered to be a consequence of collisions between molecules where the excess energy of the dye is absorbed by oxygen (Lakowicz, 1999). The suitability of PLIFI is mainly because the technique is not only limited to visualization but also enables an accurate quantification of the transferred mass. The quantification of the mass transfer is straightforward since the fluorescence level is directly related to the oxygen concentration in the liquid phase according to the (Stern and Volmer, 1919) equation:

$$
\frac{I_{Q}}{I_{0}}=\frac{\tau}{\tau_{0}}=\frac{1}{1+K_{s v}[Q]}
$$

where $K_{s v}$ is the Stern-Volmer constant $\left(\mathrm{m}^{3} \cdot \mathrm{kg}^{-1}\right),[Q]$ the quencher concentration $\left(\mathrm{kg} \cdot \mathrm{m}^{-3}\right), \tau$ and $\tau_{0}$ are the lifetimes of the fluorescence molecule with/without inhibition, and $I_{Q}$ and $I_{0}$ the fluorescence intensities in the presence and absence of quencher, respectively. In the experiment, the fluorescence intensities can be determined from the gray levels recorded by the camera. The parameters $I_{0}$ and $K_{s v}$ of the Eq. (2) can be easily determined from an experimental calibration curve, in which the inverse of different recorded fluorescence intensities $I_{Q}$ (or more precisely gray levels recorded by the camera) is plotted as a function of uniform quencher concentration (oxygen in this study).

\subsubsection{Experimental setup}

The experimental setup was quite similar to the one presented by Francois et al., (2011) as depicted in Fig. 1. A single air bubble [3] was generated by a peristaltic pump and injected through a capillary [2] 
into a transparent column [1] made of PMMA (polymethylmethacrylate). The column was filled with

104 the liquid to study (deionized water) and then deoxygenated by bubbling nitrogen before each

105 experiment. To observe the transferred mass in the bubble wake, $25 \mathrm{mg} / \mathrm{dm}^{3}$ of Ruthenium complex $\left(\mathrm{C}_{72} \mathrm{H}_{48} \mathrm{~N}_{8} \mathrm{O}_{6} \mathrm{Ru}\right.$, Nanomeps) was added to the liquid as the fluorescent dye. It should be noticed that since this dye is not directly soluble in pure water, $20 \% \mathrm{w} / \mathrm{w}$ of ethanol has to be added to the medium. To excite the fluorescent dye, a horizontal laser sheet was generated by a Nd: Yag laser [5] (Quantel, $532 \mathrm{~nm}, 10 \mathrm{~Hz}, 2 \times 200 \mathrm{~mJ})$ and placed about $10 \mathrm{~cm}$ above the column bottom. The pictures of the

110 fluorescence in the wake of the bubble were recorded by a charge-coupled device (CCD) camera [4]

111 (Imager Intense, LaVision, Germany, 12 bits, $1040 \times 1376$ pixels) located under the column and focused 112 on the laser flash. A micro objective (Micro-Nikkor $105 \mathrm{~mm} \mathrm{f} / 8$, Nikon) and three teleconverters were 113 added to the digital camera to obtain a focused area of about $3 \times 4 \mathrm{~mm}^{2}$. Since the emission wavelength 114 of the Ruthenium complex is around $670 \mathrm{~nm}$, a $570 \mathrm{~nm}$ high-pass filter was also placed on the CCD camera to block the laser light. A high-speed camera [6] (PCO 1200, 10 bits, $1024 \times 1280$ pixels) was

116 placed orthogonally to the first camera [4] and above the laser sheet. It was used to record the velocity, 117 shape and diameter of the bubble (image area $\approx 3 \times 4 \mathrm{~cm}^{2}$ ) with a recording rate of 770 frames per second 118 and started to record simultaneously with the first laser flash. A Programmable Trigger Unit (LaVision) 119 synchronized the laser and the CCD camera. The time was set to 0 when the first picture was taken. The 120 experimental system was placed in a specially designed working space, where the room 121 temperature $\left(20^{\circ} \mathrm{C}\right)$ was controlled by an air conditioner. 
128 According to the diffusive regime presented in Crank (1979), the diffusion coefficient $D$ was calculated

129

130

131

144 In the other hand, according to the probability theory, the probability density $f(w)$ of chi-squared 145 with the experimental images. The concentration $\left[\mathrm{O}_{2}\right]$ is expressed in this problem as the amount of diffusing oxygen per unit area of the image. The instantaneous concentration at a position $(x, y)$ on the cross-section of the bubble wake (bubble spot) is given by Eq. (3):

$$
\left[O_{2}\right](x, y, t)=\frac{M}{4 \pi D t} \exp \left(\frac{-\left(x^{2}+y^{2}\right)}{4 D t}\right)
$$

where $M$ is defined as the total amount of substance diffusing from a point source on an infinite plane surface, by performing the integration

$$
M=\int_{-\infty}^{\infty} \int_{-\infty}^{\infty}\left[O_{2}\right] d x d y
$$

At a fixed time $t$, for a bubble spot with area $S$, the oxygen concentration field could be expressed as:

$$
\iint_{S}\left[O_{2}\right](x, y) d x d y=\iint_{S} \frac{M}{4 \pi D t} \exp \left(\frac{-\left(x^{2}+y^{2}\right)}{4 D t}\right) d x d y
$$

For a quasi-circular spot of radius $R$, the Eq. (5) could be expressed in the polar coordinate:

$$
\iint_{S}\left[O_{2}\right](x, y) d x d y=\int_{0}^{2 \pi} d \theta \int_{0}^{R} \frac{M}{4 \pi D t} \exp \left(\frac{-r^{2}}{4 D t}\right) r d r
$$

With

It remains:

$$
w=\frac{r^{2}}{2 D t}
$$

$$
\iint_{S}\left[O_{2}\right](x, y) d x d y=M \int_{0}^{\frac{R^{2}}{2 D t}} \frac{1}{2} \exp \left(\frac{-w}{2}\right) d w
$$
distribution in $k$ freedom degrees can be written as: 
148 with $\Gamma$ the gamma function. In our study, the freedom degrees $k$ is $2(x$ and $y)$ and definitely $w>0$ (Eq.

149 (7)). Therefore, the Eq. (9) becomes:

$$
f(w)=\frac{1}{2} \exp \left(\frac{-w}{2}\right)
$$

151 Comparing the forms of Eq. (8) and Eq. (10), the following equation can be derived:

$$
\frac{\iint_{S}\left[O_{2}\right](x, y) d x d y}{M}=\int_{0}^{\frac{R^{2}}{2 D t}} f(w) d w
$$

It could provide the feasibility to determine the diffusion coefficient $D$ from the proprieties of chisquared distribution has a simple form:

$$
\begin{aligned}
P\left[w \leq \eta \mid w \sim \chi^{2}\right] & =\int_{0}^{\eta} f(w) d w \\
& =1-e^{-\eta / 2}
\end{aligned}
$$

where $P$ the probability in case $w \leq \eta$ and $w$ is distributed according to Chi-squared law. An example of values of $P$ versus $\eta$ is given in Table 1 .

161 Relation between parameter $\eta$ and $P$ of chi-squared distribution

\begin{tabular}{cc}
\hline$\eta$ & $P$ \\
\hline 1 & 0.3995 \\
2 & 0.6321 \\
3 & 0.7769 \\
4 & 0.8647 \\
5 & 0.9179 \\
6 & 0.9502 \\
\hline
\end{tabular}


163 Substituting Eq. (12) into Eq. (11), the relationship between the diffusing oxygen concentration field

164 and probability property of chi-squared distribution is given by the following equation:

$$
\frac{\iint_{S}\left[O_{2}\right](x, y) d x d y}{M}=P\left[w \leq \eta \mid w \sim \chi^{2}\right]
$$

where

$$
\eta=\frac{R^{2}}{2 D t}
$$

For the quasi-circular spot, the spot area $S$ is given:

$$
S=\pi R^{2}=2 \pi \eta D t
$$

170 From Eq.(15), for the constant $D$ and a chosen $\eta$, the area of the spot $S$ varies linearly with time $t$.

171 Through the special treatment of the experimental images pixel by pixel, the relationship between the

172 bubble area $S$ and time $t$ can be obtained. The diffusion coefficient $D$ can be determined from the slope 173 of the curve $S$ - $t$.

\subsubsection{Image processing}

In PLIFI, a typical optical experiment, various sources of noise are possible to occur on the image during the measurement. Despite the uneven distribution of dye, the image of gas concentration or fluorescence intensity presents an exponential decrease along the gas trajectory through the liquid. This phenomenon is commonly referred to an attenuation of the laser light during diffusion named Lambert-Beers decay or Beer-Lambert absorption. Such a phenomenon makes the background non- uniform and can dramatically distort the results. A threshold $\lambda$ was then set as defined in Eq. (16) to eliminate the influent of background noise and determine the boundary between the background of the image and the transferred mass by the bubble:

$$
\text { For }\left[O_{2}\right]<\lambda \times \sigma, \quad\left[O_{2}\right]=0
$$


where $\sigma$ is the estimated standard deviation of the distribution of oxygen concentrations of the image background. The choice of the threshold factor is crucial since it directly affects the quantification of the total amount of the oxygen diffusion. Depending on the image quality, the threshold factor was chosen for each image to minimize the noise and maximize the spot of mass transfer. For most cases, a threshold factor of 3 is high enough (Jimenez et al., 2013).

After applying a noise threshold to the image, for a quasi-circular spot, the concentration value $\left[\mathrm{O}_{2}\right]$ on the pixel $(x, y)$ was estimated by:

$$
\left[O_{2}\right](x, y)=A \exp \frac{-(x-X)^{2}+(y-Y)^{2}}{B}+c
$$

where $A, B$ are the parameters representing the properties of Gaussian distribution, $c$ the mean value of the residual noise on the image and $(X, Y)$ the center of the spot. With the solver fminsearch (Matlab R2012a), these five parameters were determined by minimizing the error between measured value $\left[\mathrm{O}_{2}\right]$ and the value from Eq. (17). For initialization, the parameters were set as follows:

- Initialization of $A$ : Maximum value of $\left[\mathrm{O}_{2}\right]$ on the spot

$\circ$ Initialization of $B$ : Variance of the Gaussian by placing on a fixed line passing through the center of the spot

- Initialization of $c$ : Minimum value of $\left[\mathrm{O}_{2}\right]$ on the spot

- Initialization of $(X, Y)$ : Coordinates of the maximum $\left[\mathrm{O}_{2}\right]$

The diffusing oxygen concerning the bubble spot $S$ and the total diffusing amount $M$ on the image (defined by Eq. (4)) can be calculated experimentally from:

$$
\begin{gathered}
\iint_{S}\left[O_{2}\right](x, y) d x d y=\sum_{x} \sum_{y}\left[O_{2}\right](x, y) \delta^{2} \\
M=\sum_{X_{I}} \sum_{Y_{I}}\left[O_{2}\right](x, y) \delta^{2}
\end{gathered}
$$

where $\delta^{2}$ is the area of a pixel $\left(\mathrm{m}^{2}\right), X_{I}$ (and $Y_{I}$ ) the totals of pixels along $x($ and $y$ )-direction on the image (1040*1376 in this study), respectively. 
According to the deduction in (2.1.2), the area of the circular spot $S$ thus changes linearly with time if

210 the possibility parameter $\eta$ is chosen and the coefficient $D$ is constant. For obtaining this area $S$, the following steps were preceded:

- Sum all the oxygen concentrations on the processed image where the noise has been removed;

- Sort the concentrations by ascending order;

- Perform a cumulative sum of these concentrations to achieve the proportion $P$ of the total sum of the concentrations. The value of $P$ was calculated with $\eta$ being selected arbitrarily (Eq. (12));

- Determine the number of pixels forming the cumulative sum;

- Multiplied the number by $\delta^{2}$, surface of a pixel, for having the spot area.

The relationship $S-t$ was thus obtained. Base on Eq. (15), the diffusion coefficient can be determined.

\subsection{Second method: Measurement by Probe in a Hele-Shaw cell}

The previous parts have presented the determination of the diffusion coefficient by using the visualization method PLIFI. This kind of measurement has to use powerful lasers, which is not transportable enough for applying to large-scale facilities such as a sewage treatment plant. To overcome this inconvenience, another method is present in this section. Based on the use of a Clark-type probe, this method is portable and simple to implement in various fields. The functional principle of the probe was introduced in Revsbech (1989).

\subsubsection{Experimental setup}

The experiment was applied through a flat air-liquid interface in a Hele-Shaw cell filled with quiescent deoxygenated water with air flowing at a small flow rate at the interface to generate a diffusion of dissolved oxygen from the interface. The experimental setup is described in Fig. 2. It was composed of a transparent Hele-Shaw cell and an optical system. The Hele-Shaw cell [1] was $12 \mathrm{~cm}$ high, $5 \mathrm{~cm}$ wide and $0.2 \mathrm{~cm}$ thick. The cell sides were made of polymethyl methacrylate (PMMA) with two gas orifices placed $1 \mathrm{~cm}$ below the top of the cell to allow the gas to flow [2]. 
This technique was tested experimentally for different probe locations. In fact, two types of cells of that size were tested. The main difference between these two cells was the location of the additional openings providing access to probes. The first cell had lateral openings allowing horizontal positioning of the oxygen probe [3]. The second was designed with an opening on the upper part of the cell to position the probe vertically [4]. As the measurement should be implemented far away from the cell edges to avoid any renewal of the liquid at the interface, a type of specific oxygen sensor has been used. This kind of probe has a metal reinforcement of constant cross section at its extremity (OX100 Needle Sensor $0.80 \times 40 \mathrm{~mm}$, Unisense). This reinforcement not only consolidates the probe but also makes it possible to perform far away from the edges. Deoxygenated liquid (deionized water, $10 \mathrm{~mL}$ ) was then inserted smoothly into the cell to obtain a flat interface. A low flow rate of nitrogen (about $10 \mathrm{~L} \cdot \mathrm{h}^{-1}$ ) which was controlled by a rotameter, flowed over the liquid. The gas flow was switched from the nitrogen to the air at the moment $t=0$. The sensor recorded every second the level of dissolved oxygen concentrations in the liquid. The distance between the probe tip and the gas-liquid interface was determined through a camera [5] (with lens GuppyPro $105 \mathrm{~mm}$ ). The experimental temperature was controlled at $20^{\circ} \mathrm{C}$.

\subsubsection{Determination of the diffusion coefficient}

The configuration of the Hele-Shaw cell could be supposed as a two-dimensional $(x-y)$ problem (negligibility of the contribution along the $z$-axis) and an oxygen concentration gradient is imposed only in the $x$-direction. If no convection is present along the $x$-axis, the equation of mass transfer in the HeleShaw cell can be deduced from Fick's law (Eq. (1)):

$$
\frac{\partial\left[O_{2}\right]}{\partial t}=D \frac{\partial^{2}\left[O_{2}\right]}{\partial x^{2}}
$$


where $\left[\mathrm{O}_{2}\right]$ the oxygen concentration $\left(\mathrm{kg} \cdot \mathrm{m}^{-3}\right), t$ the time since the start of the transfer $(\mathrm{s})$ and $D$ the oxygen diffusivity in the liquid medium $\left(\mathrm{m}^{2} \cdot \mathrm{s}^{-1}\right)$. In our study, $x$ represents the distance between the probe tip and the gas-liquid interface $(\mathrm{m})$. The gas flow rate being imposed along the $y$-axis and by continuity in the liquid phase, it can be assumed that no convection is present along the $x$-axis far away from the cell walls.

The duration of the experiments is relatively short (always less than 30 minutes) compared to the duration of the diffusive phenomena. Thus a semi-infinite solution can be considered.

$$
\frac{\left[O_{2}\right](x, t)-\left[O_{2}\right]_{0}}{\left[O_{2}\right]_{s}-\left[O_{2}\right]_{0}}=1-\operatorname{erf}\left(\frac{x}{2 \sqrt{D t}}\right)
$$

where $\left[\mathrm{O}_{2}\right]_{0}$ and $\left[\mathrm{O}_{2}\right]_{S}$ are the concentrations of dissolved oxygen in a deoxygenated zone and in saturation respectively $\left(\mathrm{kg} \cdot \mathrm{m}^{-3}\right)$ and $\operatorname{erf}$ the error function defined as follows (Abramowitz and Stegun, 1964):

$$
\operatorname{erf}(z)=\frac{2}{\sqrt{\pi}} \int_{0}^{z} \exp \left(-u^{2}\right) d u
$$

Indeed, Eq. (20) connects $\partial^{2}\left[\mathrm{O}_{2}\right] / \partial x^{2}$ to $\partial\left[\mathrm{O}_{2}\right] / \partial t$. Since a simple relation has been established to connect $\partial^{2}[0]_{2} / \partial x^{2}$ to the diffusion coefficient (Jimenez et al., 2012b), the similar reasoning can be conducted with $\partial\left[\mathrm{O}_{2}\right] / \partial t$.

Substituting Eq.(22) in Eq. (21), the relation between $\partial\left[O_{2}\right] / \partial t$ and $D$ is established:

$$
\frac{\partial\left[O_{2}\right]}{\partial t}=\left(\left[O_{2}\right]_{s}-\left[O_{2}\right]_{0}\right) \frac{x}{2 \sqrt{\pi D}} \frac{1}{t^{3 / 2}} \exp \left(\frac{-x^{2}}{4 D t}\right)
$$

Replace with $\alpha=1 / 2$ and $\beta=x^{2} /(4 D)$, the equation becomes:

$$
\frac{\partial\left[O_{2}\right]}{\partial t}=\frac{\left(\left[O_{2}\right]_{s}-\left[O_{2}\right]_{0}\right)}{\sqrt{\pi}} \beta^{\alpha} \frac{1}{t^{\alpha+1}} \exp \left(\frac{-\beta}{t}\right)
$$

In the other hand, according to the probability and statistics theory, the inverse gamma distribution's probability density function is defined over the support $w>0$ with defined parameters $\alpha$ and $\beta$ (Abramowitz and Stegun, 1964): 


$$
f(w)=\frac{\beta^{\alpha}}{\Gamma(\alpha)} \frac{1}{w^{\alpha+1}} \exp \left(\frac{-\beta}{w}\right)
$$

It is known that the mode of this function $f(w)$ is located in:

$$
w=\frac{\beta}{\alpha+1}
$$

From Eq. (24) and (25), it can be deduced that $\partial\left[\mathrm{O}_{2}\right] / \partial t$ is proportional to $f(w)$ of the inverse gamma distribution law. Their modes are thus located in the same coordinate. The moment $t_{\max }$ maximizing $\partial\left[\mathrm{O}_{2}\right] / \partial t$ is defined by:

$$
t_{\max }=\frac{\beta}{\alpha+1}=\frac{x^{2}}{4 D(1 / 2+1)}=\frac{x^{2}}{6 D}
$$

The distance $x$ in this case corresponds to the distance between the tip of the probe and the gas-liquid interface. The value of $x$ is measured by the camera and the oxygen concentration profile $\left[O_{2}(x, t)\right]$ can be measured simply by an oxygen probe. By investigating the derivative of the concentration profile $\left[O_{2}(x, t)\right]$ with respect to $t$, the location $t_{\max }$ can be determined. Then based on Eq. (27), the diffusion coefficient can be obtained without additional information on the liquid. It should be noted that for a Clark type probe, the signal delivered (typically in $\mathrm{mV}$ or $\mathrm{mg} \cdot \mathrm{L}^{-1}$ ) is directly proportional to the oxygen concentration. This proportionality allows obtaining $t_{\max }$ the moment when the signal of the probe becomes maximum. It means that no calibration of the probes is required to measure the diffusion coefficient.

\section{Result and discussion}

\subsection{Result of PLIFI in the bubble column}

Image processing and mass transfer quantification are realized for each spot recorded every $1 / 10$ s by the

300 CCD Camera after the bubble passing. A typical example of corrected images is given in Fig. 3 for the bubble of equivalent bubble diameter $d_{e q}=0.09 \mathrm{~mm}$. 
Through the special treatment of the experimental images describe in (2.1.3), the relationship between the spot area and time can be obtained. An example is shown in the Fig. 4.

Fig. 4 Evolution of the surface of the bubble spot transferred in the wake over time $\left(d_{e q}=0.09 \mathrm{~mm}, \mathrm{Re}=146\right.$, in a water-ethanol $20 \%$ w/w solution at $20^{\circ} \mathrm{C}$ )

This figure describes the results for an image treated with Eq.(17) (resolution by solver). According to

Fig. 4, the evolution of the spot area versus time can be divided into three phases:

- A phase without value where no solution has been obtained by the solver. This result refers to the elliptical shape of the transferred mass. It can be known that in cases of circular spots, the surface value is increasing in this phase;

- An increasing phase with a constant slope $2 \pi D \eta$. Thus, the diffusion coefficient was calculated from this slope value;

- A decay phase where the transfer is too low to be properly approximated.

319 The influence of several parameters on the results was also investigated. It was observed that the choice of probability factor $\eta$ (Eq. (14)) didn't affect the estimation of the diffusion coefficient $D$. On the contrary, the noise threshold $\lambda$ (Eq. (16)) would alter the results. An example of results corresponding to Fig. 4 is presented in the following table. ethanol mixture $(20 \% \mathrm{w})$ in $20^{\circ} \mathrm{C}$ 


\begin{tabular}{cc}
\hline Noise threshold $\lambda$ & $D\left(\mathrm{~m}^{2} / \mathrm{s}\right)$ \\
\hline 2 & $2.50 \times 10^{-9}$ \\
3 & $1.84 \times 10^{-9}$ \\
4 & $1.10 \times 10^{-9}$ \\
\hline
\end{tabular}

328 Since the noise threshold affects directly the total amount of oxygen concentrations, the estimation of the diffusion coefficient is very sensitive to parameter $\lambda$. For a suitably chosen threshold $(\lambda=3$ in this case), the diffusion coefficient obtained in the study is very close to the value $\left(\sim 1.9 \times 10^{-9} \mathrm{~m}^{2} / \mathrm{s}\right)$ which was reported in the literature for such a mixture (Jimenez et al., 2012b). Furthermore, this measurement of diffusion coefficient was applied to the oxygen bubbles of different sizes ascending in water. The results are shown in Table 3.

\section{Table 3}

Diffusion coefficients estimated in the wake of ascending oxygen bubbles of different sizes in water

\begin{tabular}{cc}
\hline$d_{e q}(\mathrm{~mm})$ & $D\left(\times 10^{-9} \mathrm{~m}^{2} / \mathrm{s}\right)$ \\
\hline 0.90 & $1.90 \pm 0.05$ \\
1.16 & $1.95 \pm 0.05$ \\
1.23 & $2.00 \pm 0.10$ \\
\hline
\end{tabular}

The data shown in this table corresponds to the results obtained from more than 50 bubbles for each case. The errors estimated were in the order of less than $5 \%$ by comparing the result from the measurements with the resolution by the solver described in the section 2.1.3. Therefore, the method was proved to be effective to measure the diffusion coefficient with good accuracy and repeatability.

Although the deduction of part 2.1.2 is based on the hypothesis that the bubble spot was circular, an extension was investigated to the non-circular case. The similar image process was carried out to obtain the spot area evolution. One of the examples is shown in Fig. 5 including both the corrected image and the corresponding evolution curve. Compared to the circular spot case, the curve of the non-circular case shows less stability but the linearity between the spot area and time could be still observed. This linearity

346 illustrates that the method for determining the diffusion coefficient is valid for the non-circular spot or 347 non-spherical bubble. It should be noted that there is an interrupt in the period of $2-3^{\text {th }}$ second. It could 
be supposed that this distortion comes from the change of the spot shapes: from ellipsoidal to nonellipsoidal since it is impossible for the spot area to decrease during the rising process of a bubble. The cause of this distortion should be investigated in future studies.

Fig. 5 Non-circular bubble spot transferred in the wake $(d e q=2.20 \mathrm{~mm}, \mathrm{Re}=465$, in a water-ethanol $20 \% \mathrm{w} / \mathrm{w}$ solution at $20^{\circ} \mathrm{C}$ ): (left) corrected image; (right) evolution of the surface versus time

\subsection{Result of Probe in the Hele-Shaw cell}

\subsubsection{Probe in horizontal position}

In order to minimize the influence of the presence of probe on the diffusion, the measurements were first tested with a probe inserted in a horizontal position. However, it was experimentally observed that the signal delivered by this probe was very sensitive and tended to diverge frequently (for a uniform oxygen concentration in the cell, the signal in $\mathrm{mV}$ measured by the probe is not constant). Moreover, the liquid tended to cling to the metal needle when the cell was filled. Therefore with a probe immersed in the liquid, it must be at least $3 \mathrm{~mm}$ of liquid above it. However, according to Eq. (27), the inflection point would range $t=12.5 \mathrm{~min}$ for a diffusion coefficient of $2.00 \times 10^{-9} \mathrm{~m}^{2} / \mathrm{s}$. For such a long time, the signal from the probe diverges sharply. Due to these difficulties, no diffusion coefficient could be estimated accurately under this configuration.

\subsubsection{Probe in vertical position}

In the contrary, the problems with a horizontal probe didn't occur when the probe was positioned vertically. In this new configuration, the measurements of diffusion coefficient were proved to be feasible. It remained difficult to verify whether the diffusion of oxygen was planar so that the mathematical approach is still valid in the proposed experimental conditions. For this purpose, a colorimetric technique was used to visualize the phenomenon of diffusion. The mechanism of the colorimetric technique was presented by Dietrich et al. (2013) and applied by Yang et al. 
(2016a\&2016b). In this study, resazurin was selected as the colorimetric indicator as its color can range from colorless (without oxygen) to pink (when oxygen was present). This coloration can be visualized and recorded using the camera.

An example of the recorded images is given in Fig. 6. It was shown that there is no evident convection transport along the $x$-direction. Thus the influence of the vertical probe on the oxygen diffusion can be neglected. However, this conclusion is only valid when the probe locates very close to the interface (about $1 \mathrm{~mm}$ between the tip of the probe and the interface). For a longer distance (over $3 \mathrm{~mm}$ ), the presence of the probe will cause the perturbation of the diffusion.

Fig. 6 Visualization of the diffusion of oxygen by colorimetry with a probe inserted vertically close to the interface $(1.95 \mathrm{~mm}$, in a water solution consisting of $0.015 \mathrm{~g} / \mathrm{L}$ resazurin, $20 \mathrm{~g} / \mathrm{L}$ glucose and $10 \mathrm{~g} / \mathrm{L} \mathrm{NaOH})$

In our experiment, the probe was placed at $1.95 \mathrm{~mm}$ below the interface so that the non-convection property is assuredly reasonable. The measurement of the diffusion coefficient of oxygen in water can be conducted. The dissolved oxygen concentration profile as a function of time is depicted in Fig. 7 . This experimental profile was compared with an analytical profile (see Eq. (21)Erreur ! Source du renvoi introuvable. with $D=2 \times 10^{-9} \mathrm{~m}^{2} / \mathrm{s},\left[O_{2}\right]_{s}=9 \mathrm{mg} / \mathrm{L}$ and $\left.x=1.95 \times 10^{-3} \mathrm{~m}\right)$. At the first minutes ( $t \leqslant 2$ minutes on Fig. 7), the oxygen concentration presented as a constant since the air flow didn't arrive at the position of probe. After the probe detected the oxygen diffusion $(2<\mathrm{t} \leqslant 8$ minutes on Fig 7), the trends of these two profiles were similar, with a slight discrepancy. This discrepancy can be explained by experimental error on the initial time of the experiment $(t=0)$. As mentioned before, for longer time ( $\mathrm{t}>8 \mathrm{~min}$ on Fig. 7), the profiles diverged. Several hypotheses can be put forward to explain this phenomenon: sensitivity of the oxygen probe, perturbation of the diffusion of oxygen, etc. However, the inflection point for estimating the diffusion coefficient is generally detected before this 
divergence as shown in Fig. 8 . The profile of the derivative $\partial\left[\mathrm{O}_{2}\right] / \partial \mathrm{t}$ was obtained through a 6 -order polynomial regression of the concentration profiles. The moments $t_{\max }$ which maximize the derivative $\partial\left[\mathrm{O}_{2}\right] / \partial \mathrm{t}$ were almost identical for the experimental and analytical profiles $\left(t_{\max }=5: 25 \mathrm{~min}\right.$ and 5:17 min, respectively). The value $t_{\max }$ led to the diffusion coefficients of $2 \times 10^{-9} \mathrm{~m}^{2} / \mathrm{s}$, which is consistent with the literature (Roustan, 2003).

Fig. 7 Comparison of experimental and analytical concentration profiles

Fig. 8 Evolution of the derivative of dissolved oxygen concentration in water $\partial\left[O_{2}\right] / \partial t$ with respect to time (the maximum positions are indicated by vertical dotted lines)

Although the result above seems promising, it should be noted that the error of the result is more significant (around 15\%) than that from a measure of PLIF (around 5\%). For reducing the error, it would be wise to place two probes at slightly different depths in the liquid and determine the diffusion coefficient by comparing the time $t_{\max }$ of the two probes. These perspective works can be implemented in the future for extending and improving the technique.

\section{Conclusion}

In this paper, two effective mathematical approaches based on the probability and statistics theory have been proposed to determine the oxygen diffusion coefficients in water. The first was to apply the technique PLIFI (Planar Laser Induced Fluorescence with Inhibition) to quantify the mass transfer in the wake of an isolated bubble $\left(d_{\mathrm{eq}}=0.9-1.26 \mathrm{~mm}\right)$ rising in the column. The chi-squared distribution was introduced to describe the diffusing oxygen concentration field, which was shown as the bubble spot on the experimental images. As a result, the evolution of the spot area as a function of time can be 
clarified in three phases: a phase without value caused by non-circularity of the spot, an increasing phase with a constant slope and a decay phase where the transfer becomes too weak to be approximated correctly. In terms of the parameters, it has been observed that the probability factor $\eta$ doesn't have impact on the estimation of the diffusion coefficient. In the other hand, the different choices of the noise threshold factor $\lambda$ will alter the results since it affects the computation of the total amount of the diffusing oxygen. The second method was conducted through a flat air-liquid interface in a Hele-Shaw cell filled with quiescent deoxygenated water. The dissolved oxygen concentrations were measured by a Clarktype probe inserted in the liquid phase. It has been turn out that there is an analogy between the oxygen diffusion and the inverse gamma distribution. The diffusion coefficient thus can be determined quickly from the dissolved oxygen concentration profile versus time. This technique has been tested experimentally for probes located in horizontal position and vertical position. It has been observed that the signal delivered by the horizontal probe is not stable and tends to diverge frequently. But the problem didn't occur for the vertical one. By using the colorimetric technique, it has been proved that the presence of the probe doesn't bring the convection transport nor disturb the dissolved oxygen concentration field.

Although these two methods were implemented in the different experimental systems (Hele-Shaw cell and bubble column), the diffusion coefficients of oxygen dissolved in water calculated from the two measurements are very close: $2.00 \times 10^{-9} \mathrm{~m}^{2} / \mathrm{s}$. Different with other methods, the two methods presented in this study do not require much information on properties of the fluids (such as the saturation concentration). It doesn't even need to calibrate the probe for the second method. It provides thus an alternative idea to study the complex media cases, such as biological media, where the transfer phenomena are difficult to characterize properly. Furthermore, these approaches permit to accurately evaluate the gas-liquid diffusivity in a very short time (several seconds by PLIFI and less than ten minutes by the probe for one measurement). The results from classically established theories and the experimental values obtained in this study are in a good agreement demonstrating the rationality of these two methods. Meanwhile, it should be noted that there are still some limitations. The derivation of the first approach (PLIFI) is established on the hypothesis of the circular spot (spherical bubble). The extension to the non-circular spot (non-spherical bubble) needs a further verification. To minimize the 
uncertainty of the result by the probe, a new configuration of two probes positioned at different depths

450 in the liquid should be tested. Further research will be implemented for investigating these problems and 451 making these techniques more powerful for diffusion characterization.

\section{Nomenclature}

Latin symbols

\begin{tabular}{|c|c|}
\hline C & Concentration $\left(\mathrm{kg} / \mathrm{m}^{3}\right)$ \\
\hline$D$ & Diffusion coefficient $\left(\mathrm{m}^{2} / \mathrm{s}\right)$ \\
\hline$d_{e q}$ & Equivalent bubble diameter $(\mathrm{m})$ \\
\hline$I_{0}$ & Fluorescence intensity without quencher, gray level \\
\hline$I_{Q}$ & Fluorescence intensity with quencher, gray level \\
\hline$J$ & Diffusive flux $\left(\mathrm{kg} / \mathrm{m}^{2} . \mathrm{s}\right)$ \\
\hline$k$ & Freedom degrees \\
\hline$K$ & Stern-Volmer constant $\left(\mathrm{m}^{3} / \mathrm{kg}\right)$ \\
\hline$M$ & Quantity of mass per unit area $\left(\mathrm{kg} / \mathrm{m}^{2}\right)$ \\
\hline$\left[O_{2}\right]$ & Oxygen concentration $\left(\mathrm{kg} / \mathrm{m}^{3}\right)$ \\
\hline$P$ & Probability \\
\hline$[Q]$ & Quencher concentration $\left(\mathrm{kg} / \mathrm{m}^{3}\right)$ \\
\hline$R$ & Radius of the image spot (m) \\
\hline$r$ & Radius (m) \\
\hline$R e$ & Reynolds number \\
\hline$S$ & Surface of the spot in the image $\left(\mathrm{m}^{2}\right)$ \\
\hline$t$ & Time (s) \\
\hline$x$ & Abscissa (m) \\
\hline$y$ & Ordinate $(\mathrm{m})$ \\
\hline
\end{tabular}


Greek symbols

$\begin{array}{ll}\Gamma & \text { Gamma function } \\ \lambda & \text { Threshold factor } \\ \delta & \text { Length of a pixel on the recorded image (m) } \\ \sigma & \text { Standard deviation } \\ \tau & \text { Lifetime of the fluorescence molecule with inhibition (s) } \\ \tau_{0} & \text { Lifetime of the fluorescence molecule without inhibition (s) }\end{array}$

Fig. 1 Schematic view of the experimental setup for PLIFI measurements

Fig. 2 Schematic view of the experimental setup for measurement by probe in Hele-Shaw cell

Fig. 3 Example of corrected images for the Case (deq $=0.09 \mathrm{~mm}, \mathrm{Re}=146$, in a waterethanol $20 \% \mathrm{w} / \mathrm{w}$ solution at $20{ }^{\circ} \mathrm{C}$ ) at different distances from the bubble

Fig. 4 Evolution of the area of the bubble spot transferred in the wake over time (deq $=0.09$ $\mathrm{mm}, \mathrm{Re}=146$, in a water-ethanol $20 \% \mathrm{w} / \mathrm{w}$ solution at $20{ }^{\circ} \mathrm{C}$ )

Fig. 5 Non-circular bubble spot transferred in the wake (deq $=2.20 \mathrm{~mm}, \mathrm{Re}=465$, in a water-ethanol $20 \% \mathrm{w} / \mathrm{w}$ solution at $\left.20^{\circ} \mathrm{C}\right)$ : (left) corrected image; (right) evolution of the surface versus time

Fig. 6 Visualization of the diffusion of oxygen by colorimetry with a probe inserted vertically close to the interface $(1.95 \mathrm{~mm}$, in a water solution consisting of $0.015 \mathrm{~g} / \mathrm{L}$ resazurin, $20 \mathrm{~g} / \mathrm{L}$ glucose and $10 \mathrm{~g} / \mathrm{L} \mathrm{NaOH}$ )

Fig. 7 Comparison of experimental and analytical concentration profiles

Fig. 8 Evolution of the derivative of dissolved oxygen concentration in water $\partial\left[\mathrm{O}_{2}\right] / \partial t$ with respect to time (the maximum positions are indicated by vertical dotted lines) 


\section{Reference}

Abramowitz, M., and Stegun, I. (1964). Handbook of Mathematical Functions: With Formulars, Graphs, and Mathematical Tables. Appl. Math. Ser.

Asher, W.E. (2009). The effects of experimental uncertainty in parameterizing air-sea gas exchange using tracer experiment data. Atmos Chem Phys 9, 131-139.

Baldauf, W., and Knapp, H. (1983). Measurements of diffusivities in liquids by the dispersion method. Chem. Eng. Sci. 38, 1031-1037.

Blackadder, D.A., and Keniry, J.S. (1973). Difficulties associated with the measurement of the diffusion coefficient of solvating liquid or vapor in semicrystalline polymer. I. Permeation methods. J. Appl. Polym. Sci. 17, 351-363.

Blackadder, D.A., and Keniry, J.S. (1974). Difficulties associated with the measurement of the diffusion coefficient of solvating liquid or vapor in semicrystalline polymer. II. Sorption-desorption kinetics. J. Appl. Polym. Sci. 18, 699-708.

de Blok, W.J., and Fortuin, J.M.H. (1981). Method for determining diffusion coefficients of slightly soluble gases in liquids. Chem. Eng. Sci. 36, 1687-1694.

Bork, O., Schlueter, M., and Raebiger, N. (2005). The Impact of Local Phenomena on Mass Transfer in Gas-Liquid Systems. Can. J. Chem. Eng. 83, 658-666.

Bouche, E., Cazin, S., Roig, V., and Risso, F. (2013). Mixing in a swarm of bubbles rising in a confined cell measured by mean of PLIF with two different dyes. Exp. Fluids 54, 1-9.

Bowyer, W.J., Xu, W., and Demas, J.N. (2004). Determining oxygen diffusion coefficients in polymer films by lifetimes of luminescent complexes measured in the frequency domain. Anal. Chem. 76, 43744378 .

Crank, J. (1979). The Mathematics of Diffusion (Clarendon Press).

Dani, A., Guiraud, P., and Cockx, A. (2007). Local measurement of oxygen transfer around a single bubble by planar laser-induced fluorescence. Chem. Eng. Sci. 62, 7245-7252.

Dietrich, N., Loubière, K., Jimenez, M., Hébrard, G., and Gourdon, C. (2013). A new direct technique for visualizing and measuring gas-liquid mass transfer around bubbles moving in a straight millimetric square channel. Chem. Eng. Sci. 100, 172-182.

Dietrich, N., Francois, J., Jimenez, M., Cockx, A., Guiraud, P., and Hébrard, G. (2015). Fast Measurements of the Gas-Liquid Diffusion Coefficient in the Gaussian Wake of a Spherical Bubble. Chem. Eng. Technol. 38, 941-946.

Duda, J.L., and Vrentas, J.S. (1968). Laminar liquid jet diffusion studies. AIChE J. 14, 286-294.

Ferrell, R.T., and Himmelblau, D.M. (1967). Diffusion coefficients of hydrogen and helium in water. AIChE J. 13, 702-708.

Fick, A. (1855). Ueber diffusion. Ann. Phys. 170, 59-86. 
Francois, J., Dietrich, N., Guiraud, P., and Cockx, A. (2011). Direct measurement of mass transfer around a single bubble by micro-PLIFI. Chem. Eng. Sci. 66, 3328-3338.

Gubbins, K.E., Bhatia, K.K., and Walker, R.D. (1966). Diffusion of gases in electrolytic solutions. AIChE J. 12, 548-552.

Guo, Z., Maruyama, S., and Komiya, A. (1999). Rapid yet accurate measurement of mass diffusion coefficients by phase shifting interferometer. J. Phys. Appl. Phys. 32, 995.

Hebrard, G., Zeng, J., and Loubiere, K. (2009). Effect of surfactants on liquid side mass transfer coefficients: A new insight. Chem. Eng. J. 148, 132-138.

Ho, C.S., Ju, L.-K., and Ho, C.-T. (1986). Measuring oxygen diffusion coefficients with polarographic oxygen electrodes. II. Fermentation Media. Biotechnol. Bioeng. 28, 1086-1092.

Jamnongwong, M., Loubiere, K., Dietrich, N., and Hébrard, G. (2010). Experimental study of oxygen diffusion coefficients in clean water containing salt, glucose or surfactant: Consequences on the liquidside mass transfer coefficients. Chem. Eng. J. 165, 758-768.

Jimenez, M., Dietrich, N., and Hebrard, G. (2012a). A New Method for Measuring Diffusion Coefficient of Gases in Liquids by Plif. Mod. Phys. Lett. B 26, 1150034.

Jimenez, M., Dietrich, N., Cockx, A., and Hébrard, and G. (2012b). Experimental study of O2 diffusion coefficient measurement at a planar gas-liquid interface by planar laser-induced fluorescence with inhibition. AIChE J. 59, 325-333.

Jimenez, M., Dietrich, N., and Hébrard, G. (2013). Mass transfer in the wake of non-spherical air bubbles quantified by quenching of fluorescence. Chem. Eng. Sci. 100, 160-171.

Ju, L.-K., and Ho, C.S. (1985). Measuring oxygen diffusion coefficients with polarographic oxygen electrodes: I. Electrolyte solutions. Biotechnol. Bioeng. 27, 1495-1499.

Kück, U.D., Schlüter, M., and Räbiger, N. (2010). Investigation on Reactive Mass Transfer at Freely Rising Gas Bubbles.

Kück, U.D., Schlüter, M., and Räbiger, N. (2012). Local Measurement of Mass Transfer Rate of a Single Bubble with and without a Chemical Reaction. J. Chem. Eng. Jpn. 45, 708-712.

Lakowicz, J.R. (1999). Advanced Topics in Fluorescence Quenching. In Principles of Fluorescence Spectroscopy, (Springer US), pp. 267-289.

Malik, V.K., and Hayduk, W. (1968). A steady'state capillary cell method for measuring gas-liquid diffusion coefficients. Can. J. Chem. Eng. 46, 462-466.

Revsbech, N.P. (1989). An oxygen microsensor with a guard cathode. Limnol. Oceanogr. 34, 474-478.

Roetzel, W., Blömker, D., and Czarnetzki, W. (1997). Messung binärer Diffusionskoeffizienten von Gasen in Wasser mit Hilfe der holographischen Interferometrie. Chem. Ing. Tech. 69, 674-678.

Roustan, M. (2003). Transferts gaz-liquide dans les procédés de traitement des eaux et des effluents gazeux. Libr. Lavoisier.

Sancho, I., Varela, S., Vernet, A., and Pallares, J. (2016). Characterization of the reacting laminar flow in a cylindrical cavity with a rotating endwall using numerical simulations and a combined PIV/PLIF technique. Int. J. Heat Mass Transf. 93, 155-166. 
Sovová, H., and Procházka, J. (1976). A new method of measurement of diffusivities of gases in liquids. 532 Chem. Eng. Sci. 31, 1091-1097.

533 Stamatopoulos, K., Batchelor, H.K., Alberini, F., Ramsay, J., and Simmons, M.J.H. (2015). 534 Understanding the impact of media viscosity on dissolution of a highly water soluble drug within a USP 5352 mini vessel dissolution apparatus using an optical planar induced fluorescence (PLIF) method. Int. J. 536 Pharm. 495, 362-373.

537 Stern, O., and Volmer, M. (1919). On the quenching time of fluorescence. Phys. Z 20, 183-188.

538 Tham, M.J., Bhatia, K.K., and Gubbins, K.F. (1967). Steady-state method for studying diffusion of gases 539 in liquids. Chem. Eng. Sci. 22, 309-311.

540 Wise, D.L., and Houghton, G. (1966). The diffusion coefficients of ten slightly soluble gasses in water 541 at $10-60^{\circ} \mathrm{C}$. Chem. Eng. Sci. $21,999-1010$.

542 Wylock, C., Dehaeck, S., Cartage, T., Colinet, P., and Haut, B. (2011). Experimental study of gas-liquid 543 mass transfer coupled with chemical reactions by digital holographic interferometry. Chem. Eng. Sci. $54466,3400-3412$.

Yang, L., Dietrich, N., Hébrard, G., Loubière, K., Gourdon, C., 2016a. Optical methods to investigate 546 the enhancement factor of an oxygen-sensitive colorimetric reaction using microreactors. AIChE J. 547 doi:10.1002/aic.15547

548 Yang, L., Dietrich, N., Loubière, K., Gourdon, C., Hébrard, G., 2016b. Visualization and 549 characterization of gas-liquid mass transfer around a Taylor bubble right after the formation stage in 550 microreactors. Chemical Engineering Science 143, 364-368. doi:10.1016/j.ces.2016.01.013 


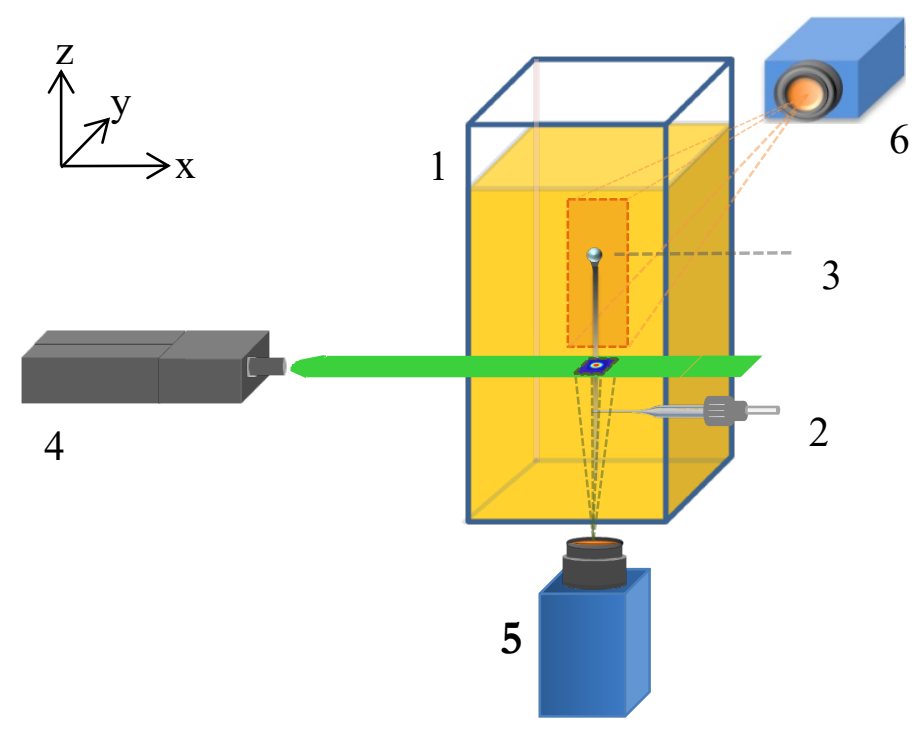

Fig. 1 Schematic view of the experimental setup for PLIFI measurements. 1. Column; 2. Gas injection system; 3. Rising bubble; 4. CCD Camera; 5. Nd: Yag laser; 6. High-speed camera 


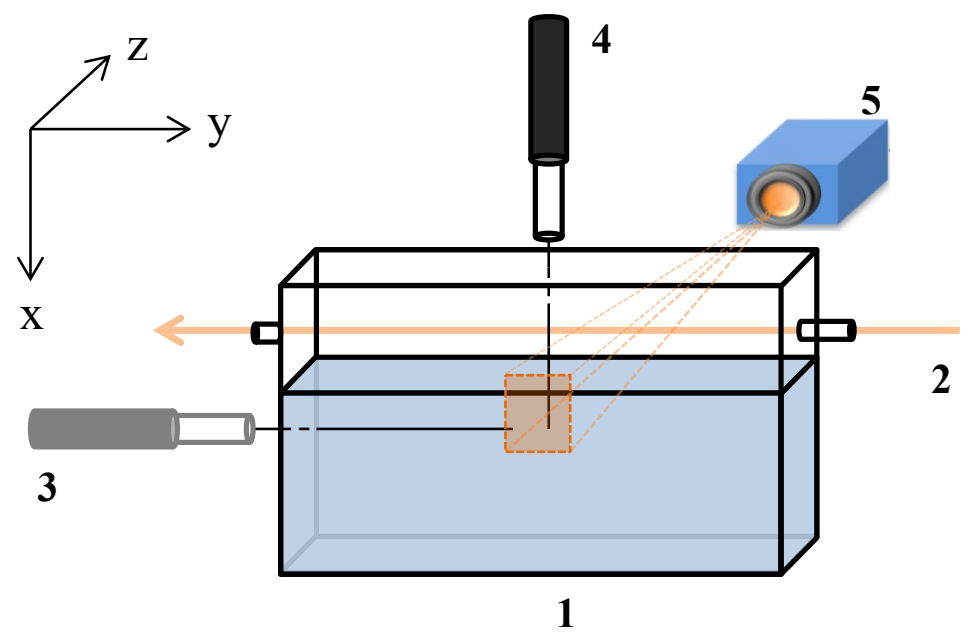

Fig. 2 Schematic view of the experimental setup for measurement by probe. 1 . Hele-Shaw; 2. Gas flow; 3. Probe in horizontal position; 4. Probe in vertical position; 5. Camera 


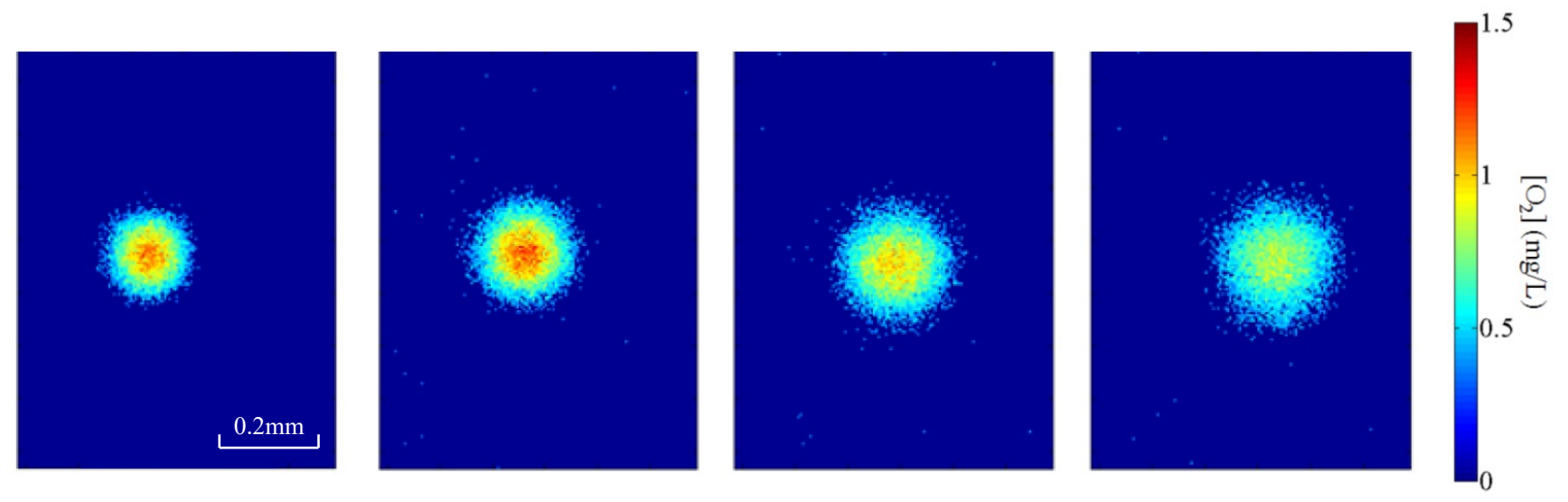

Fig. 3 Example of corrected images for the Case $\left(d_{\mathrm{eq}}=0.09 \mathrm{~mm}, \mathrm{Re}=146\right.$, in a water-ethanol $20 \% \mathrm{w} / \mathrm{w}$ solution at $20{ }^{\circ} \mathrm{C}$ ) at different distances from the bubble (35, 98, 198 and $\left.298 \mathrm{~d}_{\mathrm{eq}}\right)$ 


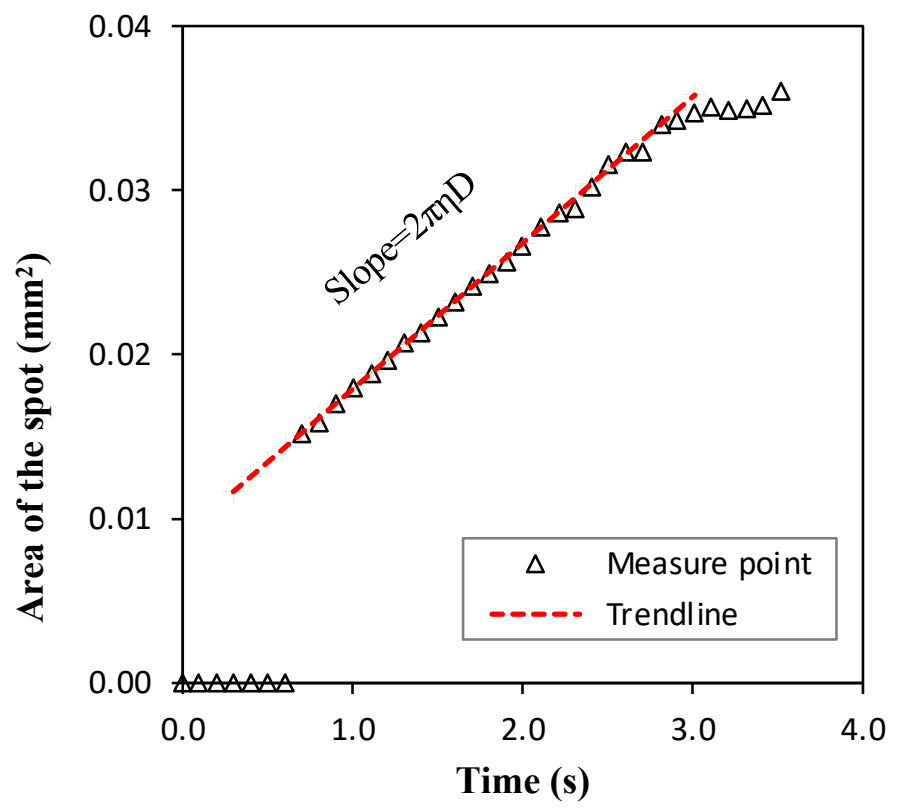

Fig. 4 Evolution of the surface of the bubble spot transferred in the wake over time $\left(\mathrm{d}_{\mathrm{eq}}=0.09 \mathrm{~mm}, \mathrm{Re}=146\right.$, in a water-ethanol $20 \% \mathrm{w} / \mathrm{w}$ solution at $\left.20{ }^{\circ} \mathrm{C}\right)$ 

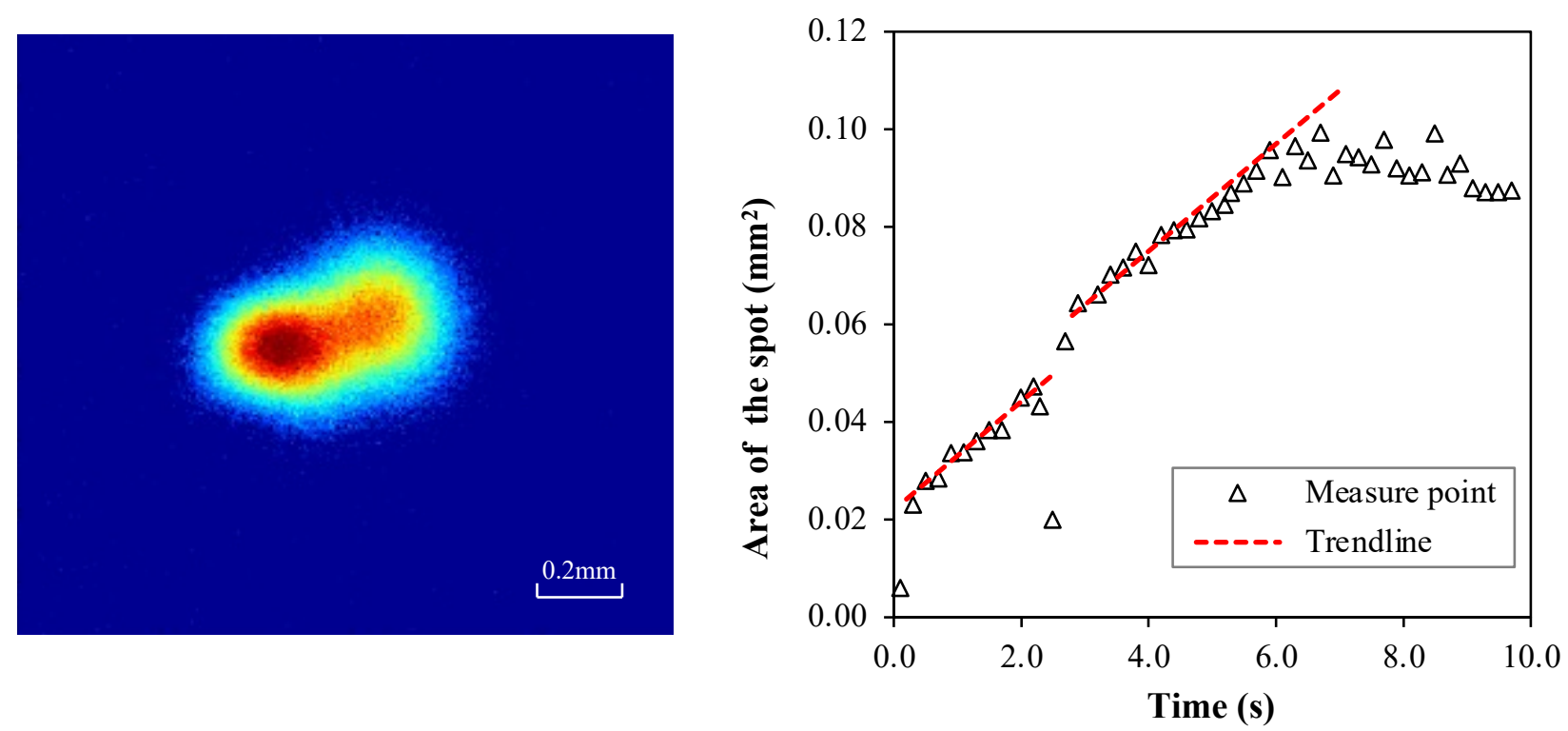

Fig. 5 Non-circular bubble spot transferred in the wake $\left(\mathrm{d}_{\mathrm{eq}}=2.20 \mathrm{~mm}\right.$, $\mathrm{Re}=465$, in a water-ethanol $20 \% \mathrm{w} / \mathrm{w}$ solution at $20{ }^{\circ} \mathrm{C}$ ) : (left) corrected image; (right) evolution of the surface versus time 

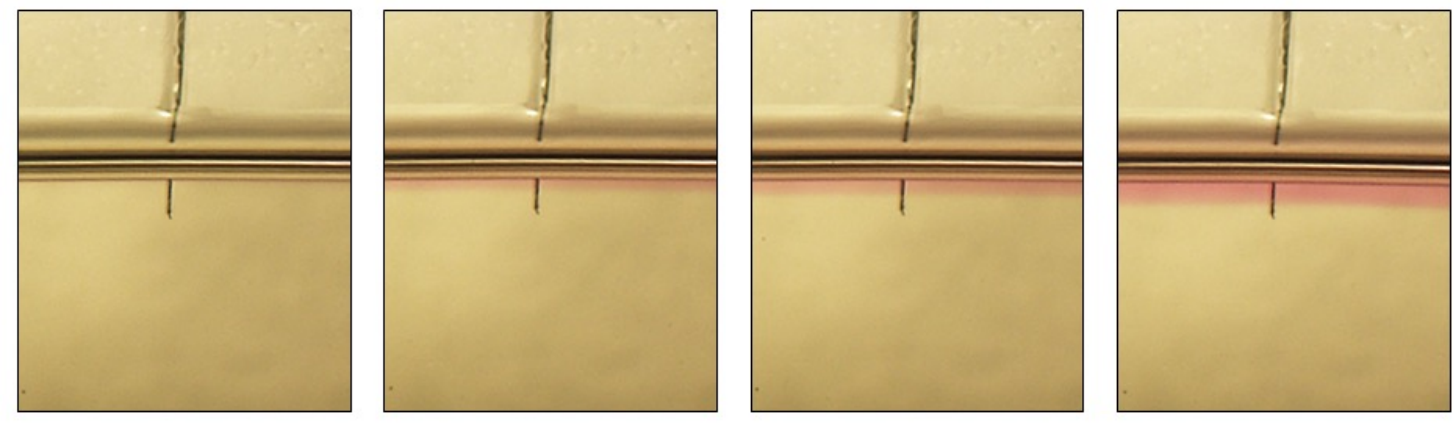

Fig. 6 Visualization of the diffusion of oxygen by colorimetry with a probe inserted vertically close to the interface $(1.95 \mathrm{~mm}$, in a water solution consisting of $0.015 \mathrm{~g} / \mathrm{L}$ resazurin, $20 \mathrm{~g} / \mathrm{L}$ glucose and $10 \mathrm{~g} / \mathrm{L} \mathrm{NaOH}$ ) 


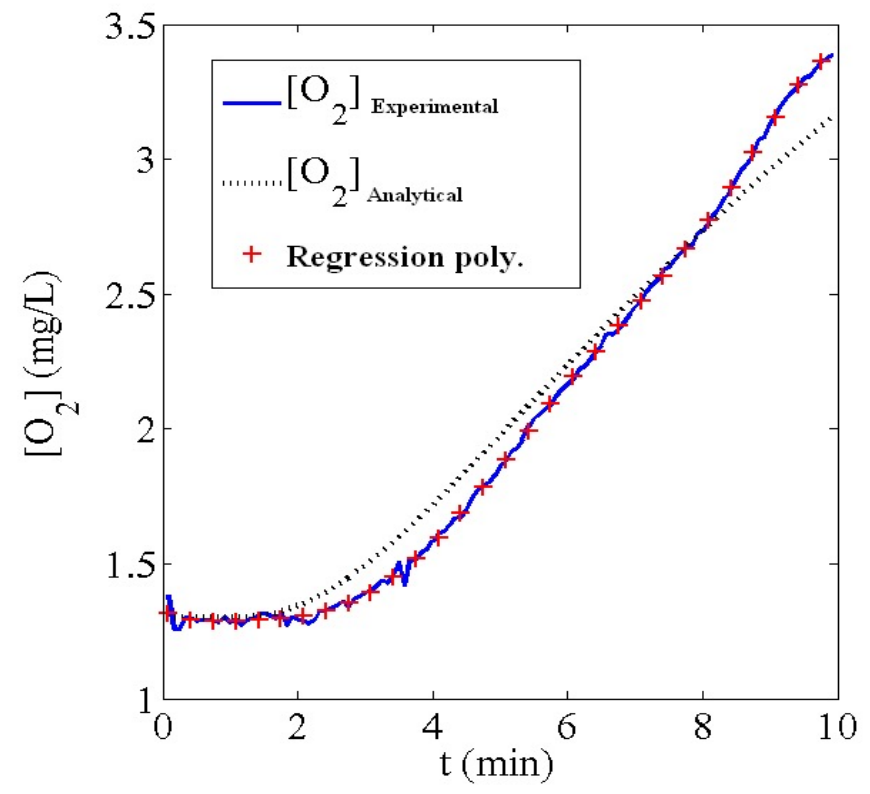

Fig. 7 Comparison of experimental and analytical concentration profiles 


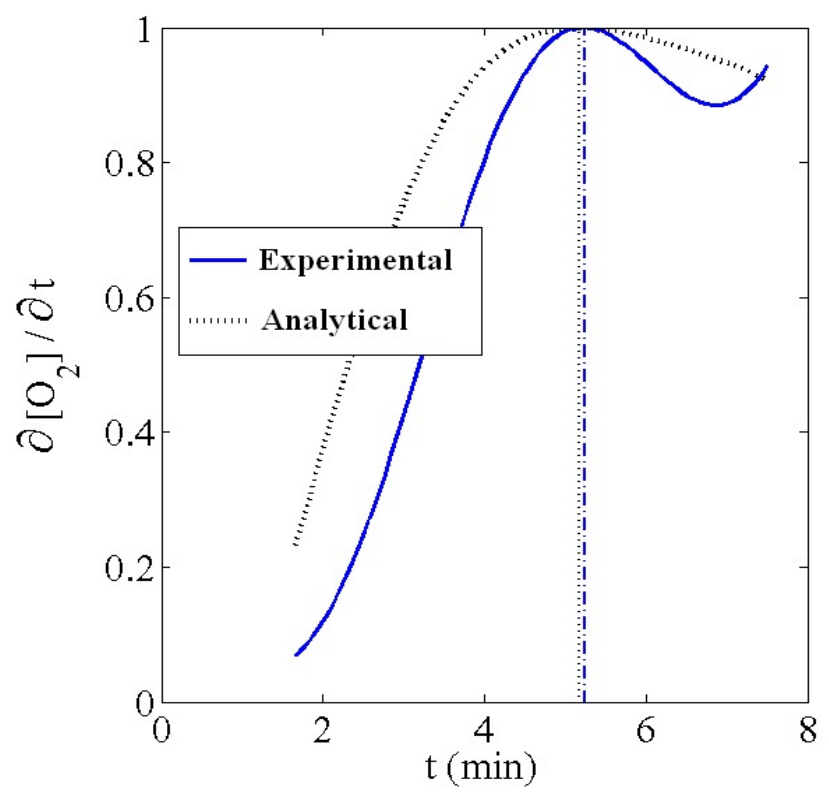

Fig. 8 Evolution of the derivative of dissolved oxygen concentration in water $\partial\left[\mathrm{O}_{2}\right] / \partial t$ with respect to time (the maximum positions are indicated by vertical dotted lines) 